\title{
The Applicability Analysis of Pragmatics in College English Teaching
}

\author{
Liu Xiaoyi \\ Foreign Language Department \\ Jilin Business and Technology College \\ Changchun, China \\ 182076127@qq.com
}

\begin{abstract}
This article firstly discusses the origin, content and main theories of pragmatics, namely, speech act theory and conversational implicature theory and relevance theory and then puts forward that the pragmatic knowledge should be stressed in college English teaching in order to deepen the students' pragmatic awareness and avoid the occurrence of pragmatic errors, thus improving the students' pragmatic competence. After the analysis of the three pragmatic theories on basis of teaching cases, it is found that pragmatics theory has a guiding significance to college English teaching practice and introducing the relevant theories of pragmatics in college English teaching can improve the learning efficiency and significantly enhance the students' discourse understanding and communication skills.
\end{abstract}

Keywords-Pragmatics; Speech act theory; Conversational implicature theory; Relevance theory

\section{INTRODUCTION}

To really understand and appropriately use a language, it is not enough to only know the pronunciation, vocabulary and grammar of the language, instead, the real function and practical significance of the language in the context must also be considered. Language teaching is a complete process, in which it is necessary to spread the language knowledge, but more important is teach students to obtain and transmit information through the proficient use of knowledge. Language knowledge comprehension cannot automatically be transformed into the language application ability. Therefore, in college English teaching, language knowledge is the foundation and communicative and pragmatic competence is training goal. He Ziran once explicitly expounded that learning a foreign language should start from pragmatics at first, and then consider internalizing foreign language grammar knowledge step by step. That is to say, college students should be cultivated from the perspective of pragmatics.

Pragmatics has been admitted as an independent discipline since the Journal of Pragmatics was founded in Netherlands in 1977. Pragmatics is a branch of linguistics studies on language understanding and use, focusing on how to understand and use a language in a different language communication environment. According to pragmatics, the use of language should not only pay attention to language form on the level of logical semantics, but also pay more attention to whether the language is used appropriately. In the process of college English teaching, it is necessary to timely introduce the pragmatic knowledge to classroom teaching and improve students' pragmatic competence, so as to realize the ultimate goal of language teaching[1].

\section{Necessity Of StREngthening PRAGMatic TEACHING IN College ENGLISH ClassRoOM}

Language is interdependent on its national culture and is the carrier of culture. Each society and nation's unique culture is deeply embodied in its language, restricting the language behavior and the appropriate use of language. Therefore, in college English teaching, cultural inclusion is already a widespread consensus. Under the background of the crosscultural communication in the globalization, people from different cultural backgrounds will have absolutely different communication and speech habits. Due to cultural differences, pragmatic difference is bound to affect the effect of communication. In order to avoid pragmatic failures in the teaching of language knowledge, teachers should adopt flexible and varied ways to import the contents of the relevant cultural knowledge. Therefore, in English teaching, we must strengthen the pragmatic knowledge of teaching and introduce the pragmatic principles into teaching content. Teachers under this background should pay attention to cultivating the students' communicative competence, enhance the students' understanding of the different communicative functions of different language forms in specific contexts and help them avoid pragmatic failures in communication. They can teach students speech act, cooperative principle and relevance theory, the important concepts and principles of pragmatics, and let students understand the language communication function of different forms under different backgrounds and the pragmatic differences between English and Chinese language. If too much emphasis is put on grammar concepts, students in the learning process will put too much emphasis on accuracy of language form and ignore the appropriateness of language use in actual situation and context, resulting in pragmatic failure. The language structure and language feature is not correspondent to each other. A kind of language feature can be expressed using a variety of language forms. The same kind of language form, because of different communicative purposes of language use, can produce different language features. Therefore, teachers should train students combine the language form, feature and specific context, helping students understand and judge the context and learn to use the corresponding form of language[2]. 


\section{Pragmatics VIEWS AND TheORIES}

\section{A. Speech act theory}

A speech act in linguistics and the philosophy of language is an utterance that has performative function in language and communication. According to Kent Bach, "almost any speech act is really the performance of several acts at once, distinguished by different aspects of the speaker's intention: there is the act of saying something, what one does in saying it, such as requesting or promising, and how one is trying to affect one's audience.” The contemporary use of the term goes back to J. L. Austin's development of performative utterances and his theory of locutionary, illocutionary, and perlocutionary acts. Speech acts are commonly taken to include such acts as promising, ordering, greeting, warning, inviting and congratulating.

\section{Speech acts can be analyzed on three levels:}

First, a locutionary act, the performance of an utterance: the actual utterance and its ostensible meaning, comprising phonetic, phatic and rhetic acts corresponding to the verbal, syntactic and semantic aspects of any meaningful utterance;

Second, an illocutionary act: the pragmatic 'illocutionary force' of the utterance, thus its intended significance as a socially valid verbal action (see below);

Third, perlocutionary act: its actual effect, such as persuading, convincing, scaring, enlightening, inspiring, or otherwise getting someone to do or realize something, whether intended or not (Austin 1962).

In the course of performing speech acts we ordinarily communicate with each other. The content of communication may be identical, or almost identical, with the content intended to be communicated, as when a stranger asks, "What is your name?"

However, the meaning of the linguistic means used (if ever there are linguistic means, for at least some so-called "speech acts" can be performed non-verbally) may also be different from the content which is intended to be communicated. One may, in appropriate circumstances, request Peter to do the dishes by just saying, "Peter ...!", or one can promise to do the dishes by saying, "Me!” One common way of performing speech acts is to use an expression which indicates one speech act, and indeed performs this act, but also performs a further speech act, which is indirect. One may, for instance, say, "Peter, can you open the window?", thereby asking Peter whether he will be able to open the window, but also requesting that he does so. Since the request is performed indirectly, by means of (directly) performing a question, it counts as an indirect speech act.

Indirect speech acts are commonly used to reject proposals and to make requests. For example, a speaker asks, "Would you like to meet me for coffee?" and another replies, "I have class." The second speaker used an indirect speech act to reject the proposal. This is indirect because the literal meaning of "I have class” does not entail any sort of rejection[3].

\section{B. Theory of conversational implicature}

American philosopher Grice put forward the conversational implicature theory in 1967. As phrased by Paul Grice, who introduced it, it states, "Make your contribution such as it is required, at the stage at which it occurs, by the accepted purpose or direction of the talk exchange in which you are engaged." The cooperative principle can be divided into four maxims, maxim of quality, maxim of quantity, maxim of relevance and maxim of manner, which are also called the Gricean Maxims, describing specific rational principles observed by people who obey the cooperative principle; these principles enable effective communication.

\section{Relevance theory}

Relevance theory is a proposal by Dan Sperber and Deirdre Wilson that seeks to explain the second method of communication: one that takes into account implicit inferences. It argues that the "hearer/reader/audience will search for meaning in any given communication situation and having found meaning that fits their expectation of relevance, will stop processing." Namely, it argues that all utterances are encountered in some context and that utterances convey a number of implicatures. For Sperber and Wilson, relevance is conceived as relative or subjective, as it depends upon the state of knowledge of a hearer when they encounter an utterance [4]. However, they are quick to note that their theory does not attempt to exhaustively define the concept of "relevance" in everyday use, but tries to show an interesting and important part of human communication, in particular ostensiveinferential communication.

\section{Pragmatic Theories’ Influence on College English TEACHING}

As an important communicative ability, pragmatics studies how to properly use the language. This kind of language ability is embodied in words and deeds to implement language features accordingly with the proper pragmatic knowledge in a specific context.

\section{A. Speech act theory's influence on English teaching}

According to the three levels of Austin's speech act theory (1962), the same word in different context will produce different ways of understanding and influence. In teaching, for example, a simple sentence "I am sleepy" has different interpretations in different contexts[5]. It can be understood as "how can the speaker be sleepy in broad daylight?" or "Is the speaker not interested in dialogue between the two?" by the hearer. It also can be understood as "the speaker really need rest after taking the common medicine for the cold cure" or "the speaker is a child and requests to go to bed when it's getting late”.

Through this case, it can be found that the speech act theory proves that language is a dynamic system, and in the different language environment, there are different ways of understanding. Therefore, when the teacher is teaching, he/she is not only supposed to teach static language, but also required to notice the use of dynamic language. In addition, in the communication between both sides, a word can not only state 
the speaker's opinion but also show the speaker's illocutionary act.

For example, "Your clothes need cleaning." itself is a statement to describe an event, but the hearer can understand it as "the speaker gives an instruction of "clean your clothes." Thus, stating the verbs of actual action can help students understand the speaker's (the teacher's) illocutionary act, and also reflects the indirect implementation of the speech act. Most language comprehension depends on the background of both sides. Teachers should not only help students to eliminate the language communication barriers, but also further develop the students' pragmatic consciousness.

\section{B. Conversational implicature theory's influence on English teaching}

In college English teaching, especially in listening teaching, its purpose is to cultivate students' listening comprehension ability to grasp the speaker's views and attitude and can further come to analysis, inference and judgment. In actual teaching process, however, many students usually only get the literal meaning and cannot understand the deeper meaning behind words, thus students' misunderstanding about real intentions will be brought about and he correct understanding of the listening material will be hindered. For instance:

Jim: Are you going with me to the park, Mom?

Mom: I'm having my hands with the students' homework.

The conversation between Jim and his Mom has four kinds of understanding. See Table 1.

TABLE I. THE FOUR KINDS OF CONVERSATIONAL IMPLICATURE OF THE SPEAKER

\begin{tabular}{|c|l|}
\hline \multicolumn{1}{|c|}{ The hearer } & \multicolumn{1}{c|}{ Conversational implicature } \\
\hline \multirow{4}{*}{ Q: What does Mom mean? } & A: She has already been to the park. \\
\cline { 2 - 2 } & B: She wants Jim to do the homework. \\
\cline { 2 - 2 } & C: She must hand in the homework. \\
\cline { 2 - 2 } & D: She is too busy to go with Jim. \\
\hline
\end{tabular}

Jim wants his Mom to take him to the park, but Mom says her hands are filled with students' homework, which apparently does not conform to the fact, in violation of the maxim of quality of the cooperative principle. When realizing his mother deliberately violates the cooperative principle, Jim can launch the real intention through analyzing discourse expression: Mom is busy correcting students' homework and can't take him to the park. Visibly, teacher can't only stay in the traditional teaching mode, but should create a real language environment for students, cultivating students' language sense. In the process of the English classroom teaching, teacher can let students play interactive roles, join in group discussion and use other teaching methods to make students realize English listening and speaking skills need to be developed in perfect union in real life. The relevant linguistic and cultural background knowledge should be delivered to students in classroom teaching so as to eliminate students' understanding barriers caused by improper language habits[6].

\section{Relevance theory's influence on English teaching}

In the teaching of English reading comprehension, although it is not direct communication activity, but is a kind of language communicative activity, which must experience the process of inferring language producer (the speaker)'s deep intention from the first layer of the language information, therefore, relevance theory is suitable for the teaching of reading comprehension. Reading comprehension procedure contains information form confession and insinuation. From the relevance theory, the hearer's inference is the core of the speech understanding, and relevance principle is the basis of deduction for the hearer. For example:

\section{Lucy: Would you have a bag of LV?}

Ann: I wouldn't have an expensive bag.

Students on the basis of the conversation will understand "An LV is an expensive bag." Therefore, reading comprehension is a process for correlation, thus infers the communicator's intention. In college English teaching, the teacher needn't translate the reading material word for word, and should let students involve in the analysis, understanding and reasoning, thus students are able to understand the sentence through the context and play subjective and initiative role in reading comprehension and discussion[7].

\section{THE APPLICATION OF PRAGMATICS IN ACTUAL TEACHING PRACTICE}

Pragmatics theory has a guiding significance to college English teaching practice. Introducing the relevant theories of pragmatics in college English teaching can improve the learning efficiency and significantly enhance the students' discourse understanding and communication skills. In the teaching practice, the relevant theories of pragmatics can solve the problem of pragmatic knowledge caused by cultural differences, explore the social factors of pragmatics and explain communication function of the structure of language and the differences of use and principles in language. College English teaching is a complete system of multi-level, each of which links to each other. Therefore, pragmatic principles should be introduced and stressed throughout college English teaching.[8]

For example, in the listening teaching practice, teachers should guide students to pay attention to the Chinese and English cultural differences, language stylistic differences and pragmatic environment differences, so as to cultivate and improve students' sensitivity to pragmatics and awareness of the importance of context in understanding discourse. Students can be encouraged to pay attention to the meaning of the discourse and the particular meaning of discourse in a specific context. Students through reading the language materials can understand the rich content implied in the text and then grasp and learn to express the intention in specific context. In the reading teaching, teachers need to proceed from the overall situation, through the overall input of language information, train the students to quickly absorb useful information and improve their abilities to accurately comprehend the deep meaning through reasonable extension and conclusion[9]. In addition, the theories of pragmatics also pay attention to the 
thinking habits and cultural differences between Chinese and western countries. Enhancing students' cultural sensitivity can also help their understanding of the reading materials.

Using some pragmatic analysis means, such as speech act and cooperative principle, can understand pragmatic effect of a speech and the deep meaning of the words from the specific context and cultural background. In writing teaching, the specific narrative context varies from the starting point of writing, which can bring about the different implicatures of the same expression, namely different pragmatic meanings. Therefore, teachers in the writing teaching process are not only supposed to teach writing skills but also required to train students' language application level, that is to say, they must guide students to pay attention to the pragmatic meaning of words, avoid pragmatic failures and help students write authentic and appropriate articles. To sum up, college English teachers play important roles in deepening teaching reform and comprehensively promoting quality education. The inclusion of pragmatics theories to college English teaching is an important way to improve students' ability of language use

\section{CONCLUSION}

The ultimate goal of language teaching is to cultivate the students' language ability and help students properly use language in communication. Teachers should constantly enrich their pragmatic knowledge and master the relevant theories of pragmatics, thus, they can continuously penetrate pragmatic knowledge to students in the daily teaching and improve students' pragmatic awareness combined with the context and the cultural background knowledge, making students involve in the intercultural communication more appropriately and correctly.

\section{REFERENCES}

[1] Levinson. Stephen C. Pragmatics [M]. Cambridge: Cambridge University Press, 1987.

[2] Leech, G. Principles of Pragmatics [M]. Longman, 1983.

[3] Ellis R. Understanding Second Language Acquisition [M].Shanghai: Shanghai Foreign Language Education Press, 1999: 27.

[4] Lado R. Liguistics Across Cultures: Applied Linguistics for Language Teachers[M].An Arbor, Michigan: University of Machigan,1957.

[5] Leech G. Principles of Pragmatics[M].London:Lonman,1983.

[6] Widdowson C. Teaching Language as Communication [M].Oxford: Oxford University Press,1999.

[7] He Ziran. The Overview of Pragmatics [M].Hunan: Hunan Education Press, 2001.

[8] He Ziran. Pragmatics and English Acquisition [M].Shanghai: Shanghai Foreign Language Education Press, 2000.

[9] He Zhaoxiong. New Edited Pragmatics Introduction[M]. Shanghai: Shanghai Foreign Language Education Press, 2000. 